\title{
ANÁLISIS NARRATIVO Y EXÉGESIS DE ÉXODO 1,15-22
}

\author{
Facundo Mela
}

Facultad de Teología de la Universidad Católica Argentina (UCA)

facundofdp@yahoo.com.ar

Resumen: El relato de las parteras de los hebreos, narrado en Ex 1,15-22, es un texto que ha tenido poca recepción tanto en la Sagrada Escritura como en los comentarios antiguos y modernos. El siguiente trabajo quiere ser un aporte a los estudios bíblicos ofreciendo un análisis narrativo y exégesis del mismo. Así también busca poner de relieve la heroica acción de Sifrá y Puá en su lucha contra la opresión del faraón y la defensa de la vida.

Palabras clave: Narrativa. Análisis narratológico. Narratología. Éxodo. Antiguo Testamento.

\section{Narratological Analysis and Exegesis of Exodus 1,15-22}

Abstract: The story of the midwives of the Hebrew, told in Ex 1,15-22, is a text which has had a little reception in the Holy Scripture and the old and modern commentaries. This article wants to be a contribution to the biblical studies offering a narratological analysis and exegesis of it. So, it tries to highlight the heroic act of Shiprah and Puah on their fight against the Pharaoh's oppression and the defense of the life.

Key Words: Narrative. Narratological Analysis. Narratology. Exodus. Hebrew Bible.

\section{Introducción}

Ex 1,15-22 relata cómo dos simples parteras, Sifrá y Puá, se oponen a las órdenes infanticidas del rey de Egipto. Movidas por su temor de Dios, 
estas dos mujeres desobedecen al monarca impidiendo el asesinato de los varones hebreos recién nacidos.

Llamativamente, este texto tuvo poco eco y recepción, tanto en la Sagrada Escritura ${ }^{1}$ como en algunos comentarios bíblicos ${ }^{2}$. Esto resulta mucho más evidente si se compara con la perícopa precedente, el relato de la opresión en Egipto (Ex 1,8-14), y la siguiente, el nacimiento y crianza de Moisés (Ex 2,1-10).

Por ello intentaremos darle al episodio de "las comadronas de las hebreas" la relevancia que juzgamos no ha tenido en su recepción aplicando el análisis narrativo.

\section{El esquema quinario}

Para el estudio de la trama utilizaremos el "esquema quinario" de Paul Larivaille ${ }^{3}$. Pensamos que el relato se adapta al orden de dicha estructura, pero no de modo estricto, pues, si bien encontramos en él todos sus elementos, pueden visualizarse un desenlace y una situación final desdoblados.

1. Situación inicial (o exposición)

2. Nudo
${ }^{15}$ El rey de Egipto dijo a las parteras de las hebreas, cuyos nombres era Sifrá, y Puá. ${ }^{16}$ Y les dijo: "Cuando asistan los partos de las hebreas y vean las dos piedras: si él es niño, entonces lo harán morir; y si ella es niña, entonces vivirá".

${ }^{17}$ Pero las parteras tenían temor de Dios

1 Sb 11,6-7; 18,5, Mt 2,16-18; Hch 7,18-19 y Heb 11,23.

2 A modo de ejemplo, SICRE, El Pentateuco, 152-153, pasa rápidamente del cambio de situación del pueblo con la subida de un nuevo faraón al trono (cap. 1) al nacimiento y salvación de Moisés $(2,1-10)$ y luego alude al episodio de las parteras como perteneciente a la tradición elohísta, sin ningún tipo de comentario ulterior. Por su parte, Auzou, De la servidumbre, dedica solo dos páginas a un comentario de Ex 1,14-20.

3 “Todo relato se define por la presencia de dos lindes narrativas (situación inicial y situación final), entre las cuales se establece una relación de transformación. La transformación hace pasar al sujeto de un estado a otro, pero ese paso debe ser provocado (nudo) y aplicado (desenlace). De ahí el esquema-quinario (denominación procedente del nombre latino del número 5); dicho esquema sitúa en cinco el número de etapas de las que se compone normalmente la trama", MARGUERAT - BouRQUIN, Cómo leer los relatos bíblicos, 71. Para la exposición del "esquema quinario" en su totalidad, cf. ib., 71-80. 
3. Acción

transformadora

4. Desenlace (I)

5. Situación final (I)

4. Desenlace (II)

5. Situación final (II) y no hicieron lo que el rey de Egipto les ordenó, sino que dejaron vivir a los niños.

${ }^{18}$ El rey de Egipto llamó a las parteras y les dijo: “¿Por qué obraron así y dejaron con vida a los niños?"19 Entonces las parteras respondieron al faraón: "Las hebreas no son como las mujeres egipcias; ellas son vigorosas; antes que llegue la partera dan a luz". ${ }^{20}$ Y Dios hizo el bien a las parteras.

Y se multiplicó el pueblo y se hicieron fuertes de modo exuberante.

${ }^{21} \mathrm{Y}$ porque las parteras tuvieron temor de Dios les dio descendencia.

${ }^{22}$ El faraón ordenó a todo su pueblo, diciendo: "A todo niño nacido lo arrojarán al río; pero a toda niña dejarán con vida"4.

1) El relato comienza con la orden que el rey/faraón da a las parteras: matar a los varones hebreos recién nacidos. La razón de la orden no se encuentra en el relato, pero el lector que ya ha leído los versículos anteriores puede intuir el porqué de la misma: detener por otro camino el crecimiento del pueblo. Ese es el objetivo que el faraón desea alcanzar, al cual subordina a las comadronas y, finalmente, a todo el pueblo egipcio, que se transformará en asesino (v. 22). Esta es la presentación de la situación inicial a partir de cuyos elementos se desarrollará la narración.

2) Luego se hace presente la tensión o nudo: "Las parteras tenían temor de Dios". La trama introduce sutilmente un factor que hará inviable la decisión/deseo asesino del rey de Egipto.

3) Esta contraposición entre la orden del rey y el temor de Dios desencadena una acción transformadora que produce un cambio en la situación inicial: las parteras dejan con vida a los niños. No solo la orden del monarca no se cumple, sino que los niños viven y las comadronas no se convierten en asesinas.

4) El deseo del faraón queda frustrado. Podríamos hablar de un verdadero contraprograma.

Como acabamos de ver, en nuestro texto encontramos dos desenlaces (donde se suprime la tensión del nudo) y dos situaciones finales.

La primera dupla de desenlace-situación final atañe al faraón, a las parteras, a Dios y a los hebreos. El rey de Egipto llama a comparecer a las parteras en su presencia. Con gran ironía, ellas tergiversan la realidad: las hebreas no son como las egipcias: "Ellas son vigorosas" (v. 19). El monarca es

4 La traducción es nuestra. 
engañado en su propia cara por dos simples comadronas, quienes le dicen que las mujeres de los oprimidos son más fuertes que las del pueblo opresor.

A su vez, Dios hace el bien a las parteras (desenlace), tanto ellas como el pueblo crecen, este último "de modo exuberante" (situación final que se da como un hecho actual y futuro). Las parteras y el pueblo experimentan una transformación: las primeras adquieren la bendición, y el pueblo se multiplica mucho más.

La segunda dupla atañe en primer lugar, nuevamente, a las parteras. Ellas, que han tenido temor de Dios, ahora explícitamente reciben el bien de Dios en la descendencia (desenlace). En segundo lugar, al faraón, los egipcios y, paradójicamente, de nuevo al pueblo hebreo, lo cual pone en evidencia, entre otras cosas, la obstinación del rey (situación final).

5) El primer conjunto de desenlace-situación final es simétrico al nudo: el temor a Dios de las parteras, que anteriormente había introducido tensión al relato, tiene sus frutos, ya que suprime la tensión narrativa y pasa a ser la causa de las transformaciones que experimentan los personajes: las parteras son bendecidas y el pueblo continúa creciendo.

6) Finalmente, y por sorpresa, se hace presente el segundo desenlace-situación final, que también es simétrico al nudo: el temor a Dios de las parteras nuevamente da sus frutos y pasa a ser la causa de las transformaciones que experimentan los personajes.

El relato remata o reduplica, al mencionar que las parteras -que ya habían sido bendecidas (v. 20)- reciben de Dios descendencia, entrando en escena este don de Dios. Se especifica en el plano de la vida el bien que Dios les hace.

Luego pareciera que, al constatar que los varones hebreos recién nacidos siguen con vida, el faraón extiende la orden a todo su pueblo: todos los egipcios deben arrojar a los niños al río Nilo. De una parte, pues, el deseo del faraón se proyecta sobre todo su pueblo. Monarca y súbditos quedan comprometidos en un mismo proyecto asesino. De otra, el río Nilo, fuente y símbolo de vida para los egipcios, se presenta como lugar de muerte para los recién nacidos hebreos. Y finalmente el relato como tal deja un final abierto. No se dice explícitamente si el pueblo egipcio cumplió o no la orden.

Llamativamente, ambas situaciones finales, sin dejar de serlo, se transforman en una nueva situación inicial: cuando el lector entre en Ex 2,1 sabrá que Moisés nace en peligro.

Podemos constatar que los dos desenlaces y las dos situaciones finales guardan una relación simétrica o paralela:

- paralelismo sintético: desenlace I (v. 20 a) - desenlace II (v. 21);

- paralelismo antitético: situación final I (v. 20b) - situación final II (v. 22). 
Por último, podemos afirmar que el relato corresponde a una trama de resolución ${ }^{5}$, pues se sitúa en un plano pragmático, donde la actuación de los personajes lleva a un cambio de la realidad: el deseo funesto del faraón se frustra; las parteras y el pueblo desbordan vida. Y, finalmente, el rey de Egipto redobla la apuesta involucrando no ya a dos simples comadronas, sino a todo su pueblo. Como contrapartida, Dios, el Dios de la vida, multiplicará al suyo.

\section{Los personajes}

En el texto encontramos una constelación de nueve personajes, con diversas características, que tejen una trama de relaciones entre ellos y experimentan cambios a lo largo del relato.

\subsection{Constelación}

Primero presentaremos los personajes principales: el monarca, las parteras y Dios. Los dos primeros poseen varios rasgos constitutivos que presenta el texto; no así Dios. El resto de los personajes poseen un valor secundario y una descripción somera.

\subsubsection{El rey de Egipto/faraón ${ }^{6}$}

Es un personaje individual, protagonista de la acción y descripto en detalle. No posee nombre, lo cual no es un dato menor. Por un lado, podría responder a una cuestión estilística: el relato no busca ser historia, sino una saga poética ${ }^{7}$. Pero, por otro, no debemos olvidar que el nombre muchas veces expresaba el destino, actividad u otra característica de una persona. Pensamos que su anonimato responde a una apreciación del mismo como

\footnotetext{
5 Ib., 92.

6 La identificación de ambos títulos en una misma persona la encontramos en Ex 3,18-19 en la LXX y en Ex 6,11 en el TM.

7 Refiriéndose al v. 8, donde aparece el nuevo rey, dice Cassuto en su comentario: “La Torá no estaba preocupada por informarnos quién era este rey. Su objetivo no era escribir historia, sino una saga poética no destinada a catedráticos, sino al pueblo como una totalidad; y la pedantería con respecto a detalles históricos no era apropiada para un poema dirigido al corazón de la nación". CASsuto, A Commentary, 9.
} 
alguien sin valor ${ }^{8}$, en contraposición a dos simples comadronas, heroínas del pueblo, que poseen nombre e incluso renombre ${ }^{9}$.

El rey/faraón es presentado, además, como un monarca poderoso, enérgico, contundente, que da órdenes y puede decretar esclavitud y muerte para los hebreos. Finalmente, insiste en su propósito asesino.

Aparece como señor de vida y muerte. Pero, en nuestro texto, esta condición no es sostenida por la acción de dos simples mujeres; más aún: el monarca es burlado por ellas.

\subsubsection{Las parteras}

Conforman un personaje colectivo, mejor aún, dual, protagonista de la acción (se las menciona siete veces en el texto) ${ }^{10}$ y con varias características descriptas. Si bien el texto, al proporcionar los nombres, indica que las parteras son dos, en el relato estas siempre actúan juntas. La posesión de nombre "no es de despreciar, considerando la frecuencia con que las mujeres son anónimas en la Biblia" "11; por el contrario, indica su importancia en el relato. Su significado posiblemente tenga alguna función en la narración, pero nos resulta desconocida ${ }^{12}$.

8 “El nombre dado en el nacimiento expresa ordinariamente la actividad o el destino del que lo lleva [...] puede evocar las circunstancias del nacimiento o el porvenir entrevisto por los padres [...] a veces es una especie de oráculo [...] En todo caso, el nombre dice el potencial social de un hombre hasta el punto de que 'nombre' puede significar también 'renombre' (Nm 16,2), y estar sin nombre es ser un hombre sin valor (Job 30,8)", X. LEón-Dufour, Vocabulario, 590.

9 Algunas obras rabínicas asocian la descendencia o casas que Dios hizo a las parteras con las casas reales, levíticas y sacerdotales. Por ejemplo: los targumim Neófiti y Pseudo-Jonatán, cf. Ex 1,21, en Martínez Saiz - Pérez Fernández, Traducciones arameas, 6 y el Talmud, cf. El Talmud de Babilonia, Sota 48.

10 Siete veces aparece la expresión "partera" en el relato: seis veces en plural refiriéndose a Sifrá y Puá. Una vez en singular y en forma genérica: “la partera” (v. 19b).

11 Cf. García Bachmann, “Qué hacían...?, 13.

12 En el Éxodo Rabbah y en el Talmud se relacionan los nombres de las parteras con sus acciones por medio de diversas etimologías. Éxodo Rabbah $1,13(1,15)$ : “¿Por qué se llama Yokebed Sifrá? Porque era la que limpiaba [mšprt] al bebé. ¿Y a Miriam Puá? Porque soplaba [np't] vino tras la acción de su madre. Otra opinión: Sifrá, porque los israelitas crecieron [prw] y se multiplicaron por su medio; Puá, porque insuflaba [mpy h] al bebé cuando se decía que estaba muerto. Otra opinión: Sifrá, porque cuidaba [šprh] sus acciones ante Dios; Puá, porque presentó [hwpy'h] a Israel ante Dios. Otra opinión: Puá, porque hizo frente [hwpy'h] al faraón y se mostró insolente con él [...] Sifrá, porque suavizó [mšprt] las palabras de su hija y tran- 
$\mathrm{Al}$ inicio del relato son presentadas como "parteras de las hebreas", siendo la cuestión de su nacionalidad un tema debatido en los comentaristas, tanto antiguos como modernos. La mayoría de los que hemos consultado se inclinan por pensar que eran hebreas ${ }^{13}$, puesto que resulta difícil concebir que mujeres egipcias asistieran a los partos de hebreas. Pero no todos coinciden con ello.

Desde un punto de vista lingüístico, la cuestión no encuentra una clara solución:

Si bien la puntuación masorética es inequívoca, el texto consonántico permite entender la palabra "hebreas" en este versículo tanto como que son las parteras que asisten a las hebreas (en ese caso podrían ser parteras egipcias) como que son ellas mismas hebreas de nacionalidad ${ }^{14}$.

Por su parte, tanto la Septuaginta como la Vulgata traducen el texto consonántico como un genitivo plural masculino (o también neutro en el caso del latín), lo cual nos lleva a pensar si los traductores fueron influidos por una lectura distinta de la que luego harían los masoretas o si prefirieron dejar abierta la interpretación de la nacionalidad de las parteras.

Situándonos en un plano sociológico, por la delicadeza y confianza que implica un parto, parece más lógico pensar más en mujeres hebreas que en egipcias ${ }^{15}$. Pero esto presenta una posible objeción: resulta difícil suponer que el faraón confiara la tarea de matar a los recién nacidos hebreos a mujeres hebreas. En esta línea, Flavio Josefo, en Antigüedades judías, como algunas leyendas hebreas se distancian de la tradición, sosteniendo que las parteras eran egipcias ${ }^{16}$. De modo similar, Römer afirma que, "a la

quilizó [al faraón]", en: GIRón BLAnc, Midrás Éxodo Rabbah I, 37-38. En el Talmud: “¿Por qué le decían Shifrá? Porque embellecía [meshaperet] al niño. Otra explicación: [Le decían] Shifrá porque en su tiempo los israelitas fructificaban [sheparu] y se multiplicaban. Puá es Miriam. ¿Por qué le decían Puá? Porque gritaba [peá] para hacer salir a la criatura. Otra explicación: [Le decían] Puá porque por medio del Espíritu Santo gritaba y decía: 'Mi madre engendrará un hijo que salvará a Israel'”, en: El Talmud de Babilonia, Sota 48.

13 Por ejemplo Andiñach, Alonso Schökel, Childs, Exum.

14 AndiÑACH, Éxodo, 35.

15 Cf. ChILdS, Éxodo, 56.

16 Flavio Josefo, Antigüedades judias, libro II, capitulo IX: “... dispuso [el rey], además, que las parteras egipcias vigilaran a las mujeres hebreas y observaran a los recién nacidos, porque quería que cumplieran esas funciones con las mujeres hebreas las parteras, que, por ser compatriotas del rey, no infringirían sus órdenes" (Flavio Josefo, Antigüedades judías, 152). Igualmente, en alguna leyenda hebrea se dice que el faraón ordenó que las mujeres hebreas fueran asistidas por egipcias para que se llevaran a cabo sus órdenes (cf. GINZBERG, The Legends of the Jews, 257). 
luz de la lógica narrativa, la identificación de las parteras como egipcias es ciertamente obvio" ${ }^{17}$.

Ahora bien, desde la perspectiva del actuar de Dios, esta cuestión de la nacionalidad se vuelve decisiva a la hora de interpretar sus acciones, como expone Langston: "Su origen étnico marca una diferencia en el relato. Como egipcias, ellas son un ejemplo de la habilidad de Dios de usar no hebreas para lograr sus objetivos. Como hebreas, ellas se vuelven símbolo de la lucha nacional por la libertad" 18 .

Para nosotros, el tema queda en suspenso. El autor/tradición ha construido un relato enigmático y abierto que no tiene intención de mostrar su nacionalidad, sino que pone el foco en aquellas que son, en cualquier caso, las destinatarias de la tarea de estas parteras: las mujeres hebreas. $\mathrm{Su}$ oficio las convertía en una ayuda necesaria para las mujeres en el parto, así como en el cuidado de la criatura y de su madre. Pero el faraón ve que ellas poseen el poder de decidir sobre la vida y la muerte ${ }^{19}$.

Algunos estudios describen más detalladamente el oficio de estas parteras desde las perspectivas arqueológica ${ }^{20}$, bíblica $^{21}$ y médica ${ }^{22}$, pero no aportan datos relevantes para nuestro análisis. Lo importante es que el relato las presenta como mujeres temerosas de Dios e implícitamente sabias, que prefieren seguir la voluntad de Dios antes que la del monarca. Para el pensamiento israelita, el temor de Dios es causa de sabiduría ${ }^{23}$. Sus convicciones y su piedad las presentan como modelos para el pueblo de Israel ${ }^{24}$. Son audaces, inteligentes, astutas e incluso irónicas: con total desfachatez le dicen al rey/faraón que las mujeres egipcias no son fuertes

17 Römer, “Moses and the Women”, 241.

18 Langston, Exodus, 18.

19 Cf. García Bachmann, “QQué hacían...?”, 14-15.

20 Cf. Roth - Roehrig, “Bricks of Birth”, 121-139; TöPfer, “Activity of Parturition”, 317-335.

21 García Bachmann, “Qué hacían...?”, 14-15; McGeough, “Birth Bricks”, 305-318; Morschauser, "Potter's Wheel”, 731-733.

22 Cf. BARnAWI - RICHTER - HABIB, “Midwifery”, 114-121; HASAN - ZULKIFLE - ANSARI Sherwani - Shakir, “Obstetrics \& Gynecology”, 35-39. LatTus - Carreño, "El asiento del nacimiento", 41-50.

${ }^{23}$ A modo de ejemplo: "El comienzo de la sabiduría es el temor de Yahvé, conocer al Santo es inteligencia” (Pr 9,10). "Principio del saber es temer al Señor; son cuerdos los que lo practican. Su alabanza permanece para siempre" (Sal 111,10).

24 "La piedad de las comadronas refleja el ideal religioso de los círculos sapienciales. Su negativa a obedecer al faraón procede de un 'temor de Dios'. Esta piedad se refleja en la sagacidad y en la capacidad para hacer frente a la acusación del faraón con argumentos racionales", CHILDS, Éxodo, 53. 
como las hebreas. Por sus acciones son bendecidas por Dios, y gracias a ellas el pueblo sigue multiplicándose. En contraposición al faraón son sostenedoras de la vida.

a) Dios es un personaje individual y protagonista. Se le describe como causa de temor religioso, bendiciendo a las parteras y al pueblo. Es fuente de vida. En este sentido, es un perfecto oponente del faraón.

b) Los varones hebreos recién nacidos. Solo se describe que están amenazados de muerte por el hecho de ser varones, lo cual los transforma en una amenaza para el reino, según piensa el rey/faraón ${ }^{25}$.

c) Las niñas hebreas recién nacidas. Se relata que se les permite seguir con vida por no representar una amenaza. Pensamos que el autor está jugando simbólicamente con la relación niños/niñas: varón/fuerza, potencia, energía; mujer/fuente de vida, etc.

d) Las mujeres hebreas son presentadas como fuertes, vigorosas, que dan vida, incluso sin la normal ayuda de las parteras.

e) Las mujeres egipcias son descritas como mujeres débiles en contraposición a las hebreas.

f) El pueblo hebreo continuó multiplicándose, haciéndose "fuerte de un modo exuberante". Ciertamente, Dios lo bendice por las acciones de las parteras.

g) Finalmente, en el v. 22, el pueblo egipcio recibe la orden infanticida del monarca.

\subsection{Trama de relaciones de los personajes}

El texto, en sí breve, presenta una constelación de nueve personajes diversos cuyos roles y acciones dan como resultado una compleja trama de relaciones, la cual muestra la riqueza del relato y la maestría estilística del autor.

25 Los destinatarios de las órdenes del faraón (vv. 16 y 22) tienen injerencia sobre los "hijos" y las "hijas" de los hebreos. Si bien en nuestro trabajo traducimos los términos bēnï y batî como "niño" y "niña" respectivamente, los términos hablan de una relación vital entre padres e hijos, de parentesco y descendencia. El uso de estos términos, en lugar de yeled (niño) o yaldah (niña), pone de relieve la maldad del rey de Egipto e incrementa el dramatismo del relato. Por otra parte, bēnï y batî también se encuentran emparentados con uno de los nombres del pueblo: $b^{\text {en }}$ ê yiśrāēel (hijos de Israel, vv. 1,1.7.9.12.14). Los hijos que están en peligro son, pues, “los hijos de Israel”, o sea, el futuro "pueblo de Dios". El término “niños" lo encontramos en los vv. 17 y 18. 
1) Esa trama pone en juego solo dos personajes individuales, diametralmente antagónicos: el rey/faraón y Dios. El primero, aparentemente todopoderoso y omnipresente, pero burlado y desobedecido por dos comadronas; el segundo, aparentemente pasivo y solo objeto de temor, pero que es causa de las acciones de las parteras y fuente de abundante bendición.

El primero es opresor; el segundo está del lado del oprimido. Este antagonismo y primer enfrentamiento entre en el "dios de Egipto" y el Dios de los hebreos se desarrollará a lo largo de la primera parte del libro del Éxodo. Este primer enfrentamiento y triunfo de Dios preanuncia el desenlace y situación final de Ex 1-15. Es un relato proléptico.

2) Todos los personajes grupales, aunque de modo distinto, están bajo el poder del faraón, más allá de sus acciones. En lo que respecta a la interacción entre estos personajes grupales podemos encontrar varias duplas contrapuestas, lo cual nos muestra, nuevamente, la complejidad del relato:

a) Las parteras y el pueblo egipcio son instrumentos de las órdenes del faraón. Son antagónicos. Las primeras desobedecen, mientras que no así el pueblo egipcio. Aunque no sabemos su comportamiento posterior, tal vez podemos inferirlo de Ex 2,1ss.

b) Varones hebreos y niñas hebreas son personajes indefensos y pasivos. La vida o la muerte de estos depende de su sexo. Con ironía y sutileza, pero sin enfrentarlos, se relaciona el "sexo fuerte" con la muerte y el "sexo débil" con la vida.

c) Mujeres hebreas y mujeres egipcias están contrapuestas por su condición ante la opresión y la fortaleza (durante el parto). Las primeras pertenecen a un pueblo oprimido, pero son fuertes; las segundas pertenecen al pueblo opresor, pero son presentadas como débiles.

d) El pueblo egipcio y el pueblo hebreo son obligados a transformarse en enemigos, a tener una relación despiadada de opresor-oprimido, de víctima-victimario, no por elección propia, sino por voluntad del monarca.

En todas estas duplas grupales se constata cómo el débil u oprimido es más fuerte que el fuerte u opresor; cómo el poder de la vida es más fuerte que el de la muerte; cómo el Dios de los hebreos es más poderoso que el de Egipto. Estas contraposiciones plantean una pregunta irónica: ¿quién es fuerte y quien débil?

3) Otra dupla, antagónica y desproporcionada, es la del rey/faraón y las parteras, un personaje individual enfrentado a uno dual; un dios terreno enfrentado a dos comadronas; un monarca que ordena y dos mujeres que 
desobedecen; un todopoderoso que pide cuentas y dos simples mujeres que se burlan, en el tenor del relato, de él. En esta dupla, tan desproporcionada, encontramos otra vez una gran dosis de ironía y coraje, pues ellas "reconocen una autoridad superior a la del faraón; en concreto, con su comportamiento afirman que el faraón no tiene autoridad sobre la vida y la muerte de los neonatos" 26 .

Este enfrentamiento marca el tono de la narración bíblica: la confrontación entre poderosos y débiles ${ }^{27}$. Sus acciones son fundamentales en la liberación del pueblo de la esclavitud ${ }^{28}$; se niegan a aceptar las órdenes del opresor y protegen la vida ${ }^{29}$. No temen mentir para salvar vidas y llevan adelante "el primer acto de 'desobediencia civil' de la historia de salvación" ${ }^{30}$, transformándose en un modelo de temor de Dios ante la barbarie $^{31}$.

4) Por último, hallamos dos duplas que aparecen en el relato de un modo sutil:

a) Los hebreos y los egipcios, no tanto como nacionalidad, sino como grupos de pertenencia. El primer grupo es oprimido y el segundo, opresor; el Dios de los primeros bendice y da descendencia; el de los segundos da órdenes asesinas y quiere destruir. En esta dinámica, las parteras hacen una opción y eligen estar del lado hebreo.

b) Lo femenino y lo masculino: en el relato, las mujeres adultas, a excepción de las egipcias, que el lector podría considerar débiles, son, por el contrario, valientes, fuertes. Dan vida, la protegen y hasta, como las comadronas, se arriesgan al peligro. Por su parte, los personajes masculinos, a excepción de Dios, ordenan matar (faraón), su vida está en peligro (niños hebreos), son pasivos (pueblo hebreo) o son receptores de órdenes asesinas (pueblo egipcio).

26 SKA, “Il diritto e la legge...", 471.

27 Cf. WeEms, “The Hebrew Women”, 25-34.

28 Cf. Porcile Santiso, Con ojos de mujer, 141.

29 Cf. An Asian Group Work, “An Asian Feminist Perspective”, 266.

30 Cf. Porcile Santiso, Con ojos de mujer, 139.

31 “En el comienzo de la historia [del Éxodo] y asociado al cumplimiento de la promesa de multiplicarse, encontramos que las parteras son presentadas como modelos de fe a seguir en su desobediencia civil. Su rechazo a implementar la política genocida está motivado por su elección de temer a Dios antes que al faraón", SHERIFFS, "Moving on with God", 53. 


\subsection{Transformaciones de los personajes}

1) A lo largo del texto, el rey/faraón se mantiene en una misma tesitura, que se ahonda: matar a los varones hebreos recién nacidos. Dado que las parteras no siguen su orden, la recrudece y amplía el marco de los ejecutores.

2) Por su parte, las parteras desobedecen al monarca y temen a Dios. Finalmente, son bendecidas con su descendencia. En cierta medida se convierten en plurales.

3) Por lo que respecta a Dios, este solo había sido mencionado como sujeto de temor (v. 17). Entrará en escena por primera vez en el libro del Éxodo (v. 20), aunque de modo actancial muy breve, saliendo así de su pasividad narrativa, actuando a favor del pueblo, como, por otra parte, lo hará a lo largo del libro.

4) Los varones recién nacidos, quienes al principio solo debían ser asesinados por las parteras, luego deberán ser eliminados por el pueblo egipcio. Así como el faraón recrudece su deseo, los niños quedan a merced de su furibundo empeño. Por su parte, las niñas recién nacidas nunca se encontrarán en peligro.

5) El pueblo hebreo, pese a las órdenes del rey/faraón, destinado a la esclavitud y muerte, seguirá multiplicándose.

6) El pueblo egipcio, pasivo en un primer momento, se mimetizará con la figura del monarca.

Como conclusión, el nivel de análisis narrativo hasta ahora practicado ha puesto de relieve elementos no visualizados por el lector históricocrítico, como el juego y trama de relaciones (positivas y negativas) entre los personajes. Esto nos ha permitido profundizar, en otro nivel, en la inusitada trama del texto, aparentemente tan breve y anecdótica.

\section{Sentimientos que despiertan}

El rey/faraón produce rechazo y antipatía, ya que condena a muerte a bebés y se empecina en ello, recrudeciendo la persecución de los niños. Por otro lado, al ser burlado por las comadronas, el lector percibe que no es todopoderoso, y su figura se reviste de un carácter cómico: el poderoso burlado.

Las parteras producen empatía, ya que desafían las órdenes del rey/ faraón y se arriesgan para salvar la vida de los niños. Son percibidas como las heroínas que se enfrentan a un enemigo mucho más poderoso, al cual vencen con astucia y valor. 
Al comienzo, Dios produce una cierta antipatía. ¿Por qué decimos esto? Él está ausente. Pudiera parecer indiferente, lejano. Pero con su entrada en escena, breve pero efectiva, produce un cambio en los sentimientos del lector, quien entonces comienza a sentir empatía por sus acciones.

Los varones hebreos recién nacidos producen simpatía, ya que sus vidas corren peligro solo por el hecho ser hebreos, varones, y nacer en ese momento. Son injustamente condenados a muerte.

Las niñas hebreas recién nacidas producen simpatía, ya que son miembros de un pueblo oprimido, aunque sus vidas no están en peligro.

Las mujeres hebreas producen empatía, ya que son fuertes y valientes, capaces de dar a luz solas (con todo el riesgo y dolor que esto conlleva) para salvar a sus hijos.

Las mujeres egipcias producen una cierta simpatía y, por momentos, un poco de lástima, ya que el relato las presenta débiles, incapaces de dar a luz a solas.

El pueblo hebreo produce simpatía, ya que sufre injustamente la opresión y la matanza, aunque por momentos da un poco de antipatía por una cierta pasividad ante las órdenes del faraón.

El pueblo egipcio produce antipatía al tener que llevar a cabo las órdenes del faraón.

\section{Posición del lector}

El lector sabe todo lo que ocurre en el relato, incluso los sentimientos religiosos de las parteras y las acciones futuras de Dios. En ese sentido es tan omnisciente como el relator.

Ahora bien, en este punto quisiéramos subrayar que las acciones de Dios en buena medida quedan fuera del relato actual, porque son acciones que se cumplirán en un futuro, que los personajes del relato desconocen. De este modo, Dios y su actuación son solo conocidos por el lector. Aunque este no conoce el cómo. El lector queda suspendido y en intriga. Con ello pensamos que el autor intenta crear en la mente del lector un apaciguamiento. A partir de ahora, él sabe que, pase lo que pase, el Dios de la vida cuidará de su pueblo.

\section{Temporalidad}

Como pudimos observar en la estructura a partir del esquema quinario, el texto sigue un orden cronológico estricto que ensambla presente, pasado y futuro. 
La narración es un relato folclórico de gran simplicidad que pivota en torno a dos simples comadronas que interactúan con el poderoso rey de Egipto $^{32}$.

\subsection{Los tiempos del relato}

En apenas ocho versículos se desarrollan hechos acaecidos en cinco períodos temporales:

1) la orden del monarca (vv. 15-16);

2) la desobediencia de las parteras (v. 17);

3) el diálogo entre ellas y el monarca (vv. 18-19);

4) la bendición de Dios y el crecimiento del pueblo (vv. 20-21);

5) la nueva orden del monarca (v. 22).

Aquí podemos apreciar la velocidad de la narración y la diferencia entre el "tiempo narrado" y el "tiempo narrante" 33 .

El texto le dedica dos versículos a la orden del faraón, algo que podemos presumir que ocurrió en minutos. Un versículo a la desobediencia de las parteras, algo que pudo haber ocurrido en el intervalo de semanas, meses, incluso años.

El diálogo entre el monarca y las parteras es narrado en dos versículos, algo que nuevamente debió de ocurrir en minutos.

La bendición de Dios y el crecimiento del pueblo se narra en un versículo. Un hecho que tendrá una duración de meses, incluso años, teniendo en cuenta los tiempos de gestación y nacimiento de los niños. Por una parte, la fecundidad del pueblo queda, para el lector, garantizada. Por otra, el texto adquiere un perfil proléptico, una dimensión de futuro abierto.

Un solo versículo cierra la narración con la nueva orden del faraón, que parece instantánea, pero que también se abre a un futuro indeterminado. Un futuro de al menos un año, como se puede apreciar en Ex 2,1-2 ${ }^{34}$.

32 La misma estrategia narrativa pareciera darse cuando el rey da la orden a su pueblo. Esta sería una orden directa emanada del rey a su pueblo más que una orden dada por pregoneros, edictos u otro medio de la época. Cf. CASsuto, A Commentary, 14-15.

33 “El estudio de la temporalidad narrativa se consagra a ese juego de relaciones entre el tiempo narrado, que es el tiempo de la historia relatada, y el tiempo narrante, que es el del relato", Marguerat - Bourquin, Cómo leer los relatos bíblicos, 141.

34 Si se tiene en cuenta la unión de los padres de Moisés, su concepción, gestación, nacimiento y los tres meses en que fue ocultado, dicha secuencia debió de haber sido de al menos un año. 
A modo de síntesis podemos en el siguiente gráfico la secuencia de la siguiente manera:

\begin{tabular}{|c|c|c|c|}
\hline & & $\begin{array}{l}\text { tiempo narrado } \\
\text { (minutos, horas, } \\
\text { días, meses, } \\
\text { años, etc.) }\end{array}$ & $\begin{array}{l}\text { tiempo narrante } \\
\text { (versículos, } \\
\text { capítulos) }\end{array}$ \\
\hline 1 & la orden del monarca (vv. 15-16) & Pocos minutos & Dos versículos \\
\hline 2 & la desobediencia de las parteras (v. 17) & Semanas, meses & Un versículo \\
\hline 3 & $\begin{array}{l}\text { el diálogo entre el monarca y las parteras } \\
\text { (vv. 18-19) }\end{array}$ & Pocos minutos & Dos versículos \\
\hline 4 & $\begin{array}{l}\text { la bendición de Dios y el crecimiento del } \\
\text { pueblo (vv. 20-21) }\end{array}$ & $\begin{array}{l}\text { Semanas, meses, } \\
\text { años }\end{array}$ & Dos versículos \\
\hline & la nueva orden del monarca (v. 22). & Pocos minutos & Un versículo \\
\hline
\end{tabular}

\subsection{La velocidad del relato}

El cuadro presentado, además de mostrar de modo gráfico los tiempos del relato, nos permite también apreciar su velocidad.

En primer lugar, vemos su desproporción: las órdenes y el diálogo son relatados de un modo más extenso que los hechos, pese a que su duración cronológica es muchísimo más breve. Esto nos hace apreciar su importancia en el relato.

El relato posee además tres pausas descriptivas, las cuales detienen por unos instantes el discurrir de la historia y describen algún elemento que permite comprender su trama.

La primera pausa (v. 17a): "Pero las parteras tenían temor de Dios", detiene la narración y, a través de la condición omnisciente del autor, nos permite entender por qué las parteras desobedecerán al faraón.

La segunda pausa (v. 20a): "Y Dios hizo el bien a las parteras", y la tercera (v. 21a): "Y porque las parteras tuvieron temor de Dios", dan las razones del crecimiento del pueblo y los beneficios recibidos por ellas.

De este modo, recapitulando "los tiempos del relato" y sus "pausas", podemos apreciar en profundidad su "velocidad".

Lentamente se relata la orden de rey (vv. 15-16); se detiene para describir los sentimientos religiosos de las parteras (v. 17a). Luego se acelera para referirse a sus acciones (v. 17b). Posteriormente, se desacelera el hilo de la trama y hallamos el diálogo entre el faraón y las comadronas (vv. 18- 
19). Nuevamente encontramos una pausa que hace referencia a la bendición divina (v. 20a), y rápidamente alude al crecimiento del pueblo (v. 20b), para detenerse nuevamente a hacer referencia a los sentimientos religiosos de las comadronas (v. 21a), y con gran velocidad se describe el premio de la descendencia (v. 21b). Por último, se desacelera el hilo del relato y lentamente se describe la segunda orden del faraón (v. 22).

Concluyendo el tema de la temporalidad del relato, recordemos que al comenzar el análisis aludimos a que nuestro texto ensambla de modo notable presente, pasado y fututo.

Hay un ayer, un pasado, el pueblo se ha multiplicado por favor de Dios y ha caído en la opresión del faraón y los egipcios. Vemos aquí la oposición entre vida/esclavitud.

Faraón y comadronas, quienes tienen temor de Dios, actúan en el presente. Ahora la oposición es destrucción/vida.

Finalmente, el faraón desea dominar el futuro de los dos pueblos. Pero, nuevamente, de forma subrepticia, el texto nos devela que Dios se reserva el futuro. Emerge así la oposición muerte/vida. De este modo, la trama vuelve a poner de relieve que Elohim es Señor del tiempo.

\section{La voz narrativa}

El narrador es externo al texto: relata en tercera persona; ausente, no se encuentra dentro de la narración; y omnisciente, porque sabe todo lo que ocurre, incluso los sentimientos de las parteras, y anticipa los frutos de la bendición divina.

\section{La perícopa en el macrotexto (Ex 1,1-2,10)}

Ex 1,15-22 actúa como una "perícopa puente" entre la opresión (1,114) y el nacimiento del futuro liberador del pueblo hebreo $(2,1-10)^{35}$. El macrotexto tiene en la figura de Moisés su centro: "Basta leer el comienzo del capítulo 2 para darse cuenta de que el pasaje de que estamos hablando

35 “La unidad podría ser dividida en tres partes. Ex 1,1-14 introduce a los 'hijos de Israel' al lector y describe cómo era el trato de estos en la tierra de Egipto. Ex 1,15-22 sirve como puente [subrayado nuestro] y muestra al faraón complotando para destruir a los hijos de Israel utilizando a las parteras. Ex 2,1-10, que está en equilibrio con 1,1-14, se focaliza en un hijo de Israel y muestra cómo el intento de genocidio le afecta", WICKE, "The Literary Structure”, 99. 
es su preparación. No se habla del peligro corrido por los recién nacidos sino en razón de uno de ellos: Moisés" ${ }^{36}$. Por su parte, Ska, refiriéndose a la historia del nacimiento de Moisés, expresa: "Este relato [Ex 2,1-10] supone la narración precedente y la orden del faraón de arrojar al Nilo a todos los niños varones hebreos" ${ }^{37}$. Por otra parte, esta función de "puente" no está exenta de tensiones, incongruencias y cuestiones no resueltas del todo ${ }^{38}$.

Por otra parte, dado que el macrotexto como tal no es el objeto específico de nuestro estudio, solo nos detendremos en la trama y la configuración de los personajes que aparecen en él (Ex 1,1-2,10).

\subsection{La trama de Ex 1,1-2,10}

Desde la perspectiva del macrotexto, que es el inicio del libro del Éxodo, nuestra perícopa es su segundo relato.

- En 1,1-14 se relata quiénes eran los hijos de Jacob que entraron con su padre en Egipto; el crecimiento de los israelitas, hasta ser muy numerosos, signo del cumplimiento de la bendición de la descendencia (1,1-7). A renglón seguido, la llegada de un nuevo rey, que desconocía la existencia de José, cambia el escenario político y ante ese pueblo fuerte y grande, potencial enemigo según su punto de vista, decreta trabajos forzados con el objetivo de detener su multiplicación. Pero, pese a ello, no lo logra: la opresión exacerba el crecimiento del pueblo y el faraón recrudece la cruel servidumbre. Si bien el texto no lo dice expresamente, el lector puede suponer que los israelitas se multiplicaban mucho más.

- En 1,15-22, la suerte de los hebreos empeora. Con seguridad, al ver el crecimiento continuo del pueblo, el faraón decreta la muerte de sus varones recién nacidos, quedando en peligro el don de la descendencia. Ante esto, las parteras, temerosas de Dios, como hemos visto reiteradamente, desobedecen la orden del faraón y los niños se salvan, obteniendo así descendencia y bendición divina para ellas y el pueblo. Finalmente, la orden de matar a los recién

36 Auzou, De la servidumbre, 67.

37 Ska, Pentateuco, 284.

38 A modo de ejemplo afirma De Vaux: “... la supresión de los recién nacidos es contraria a la intención del faraón de tener obreros para sus trabajos y no prepara el empeoramiento del trabajo [...] Es una tradición antigua, pero diferente de la del trabajo obligatorio, y prepara el relato del nacimiento de Moisés (Ex 2,1-10)", DE VAUX, Historia antigua de Israel, 318. 
nacidos se extiende a todo el pueblo egipcio, al que se le ordena arrojar a los niños hebreos al río.

- En 2,1-10 se relata el nacimiento de Moisés. Si bien el texto anterior no menciona si el pueblo egipcio siguió la orden del faraón, el contexto de peligro en que nace Moisés lo da por supuesto. Pero, pese a ello, es salvado por la astucia de su madre y hermana y la compasión de la hija del faraón. Ese niño, que será clave para la salida del pueblo del opresor Egipto, es como una primicia, "salvado de las aguas" asesinas.

Por tanto, desde el punto de vista de la trama, el macrotexto nos permite comprender mejor, por un lado, la secuencia del relato y, por otro, volver a mirar su función en el macrotexto. En este sentido, Ex 1,15-22 no es solamente un texto-puente, sino que tiene una consistencia propia y un papel específico: Dios entra en escena en la vida del pueblo y se comporta en los términos de la Alianza.

\subsection{La configuración de los personajes del macrotexto}

Veamos la constelación de personajes y cómo son presentados por orden de aparición. Dado que ya hemos tratado de los personajes que intervienen en Ex 1,15-22, solo nos detenemos en los que actúan en la primera y tercera escena del macrotexto.

1) Los israelitas o hijos de Israel son un personaje colectivo y protagonista. En Ex 1 se describe su origen patriarcal, su estadía en Egipto, su crecimiento exorbitante, los trabajos forzados que sufren y la amenaza que viven sus recién nacidos, quienes se salvan por la acción de las parteras. Por otra parte, en Ex 2,1-10 desaparecen de la escena como colectivo.

Observamos de paso cómo los israelitas quedan ligados al tema del nombre: se sabe el nombre de los epónimos, de las parteras, de la ascendencia de Moisés: Leví, y al mismo tiempo el texto ofrece una explicación del nombre del futuro héroe. Hay nombres. Hay identidad y futuro. No así los egipcios.

2) El rey/faraón es un personaje individual y protagonista. Se describen su astucia y los argumentos que lo llevan a decretar los trabajos forzados, mostrándolo como un personaje que establece estrategias de gobierno, pero con saña; su crueldad aparecerá luego, cuando decrete, con una acción tal vez desesperada, la muerte de los recién nacidos israelitas. 
Luego, en Ex 2,1-10, si bien desaparece de la escena, se le menciona indirectamente en las referencias a su hija. Visto en conjunto, se aprecia mejor cómo su maldad va in crescendo, pero también se le percibe como un monarca todopoderoso al que nadie obedece (¿a excepción de su pueblo?); no tiene el control total de la realidad: el pueblo israelita crece pese a los trabajos forzados. E incluso le engañan: las comadronas no siguen sus órdenes y estratégicamente le mienten con gran ironía. Su propia hija no sigue su decreto, e incluso lleva al niño hebreo rescatado a la mismísima corte.

3) Los capataces son un personaje colectivo mencionado solo en Ex 1,11 como los encargados de hacer que el pueblo cumpla los trabajos forzados.

En Ex 1,15-22, como ya vimos, aparecen el faraón, las parteras, los niños israelitas y las niñas hebreas, las hebreas, las egipcias, Dios y el pueblo egipcio. A excepción del rey/faraón y del pueblo egipcio (cf. 1,9), el resto de los personajes no son mencionados ni en la perícopa anterior ni en la posterior.

En Ex 2,1-10 entran en escena nuevos actores:

4) El padre de Moisés es personaje individual de quien solo se dice que es miembro de la casa de Leví y que tomó como esposa a la madre de Moisés.

5) La madre de Moisés es un personaje individual y esta descripta de modo más detallado. Ella también es miembro de la casa de Leví, da a luz a su hijo, lo esconde, prepara el cesto donde irá Moisés sobre el Nilo. Ella luego será incluso su nodriza. El texto la presenta como una mujer valiente que desobedece de modo activo la orden del faraón.

6) Moisés es un personaje individual y protagonista, quien, si bien es totalmente pasivo en el relato, hace su entrada en el libro del Éxodo y en la historia del pueblo. Se le describe como "hermoso" (Ex $2,2)$ y que se salva de modo casi milagroso por la astucia de su madre y su hermana. Finalmente, se informa que fue como un hijo para la hija del faraón, con todo lo que ello implica: educación, privilegios, etc. Como broche final se le otorga nombre al niño ("Moisés") y se explica narrativamente su significado.

7) La hermana de Moisés es un personaje individual, astuta e inteligente, que no solamente veló por su hermano, sino que también logró que su madre actuara como nodriza de su propio hijo, obteniendo incluso un beneficio económico. 
8) La hija del faraón es un personaje individual y aparece como una joven capaz de conmoverse ante un niño abandonado, aunque este sea hebreo. Una compasión que se concreta en su adopción y crianza. Si bien el texto no hace referencia al hecho de si conocía o no la orden de su padre, el faraón, ella "lo tuvo por hijo" (Ex $2,10)$, lo cual indica nuevamente con ironía que el monarca no es obedecido ni por su propia hija.

9) Las doncellas de la hija del faraón son un personaje colectivo que completa la escena. Ellas solo acompañan a la hija del faraón sin cumplir ningún rol específico; salvo la criada enviada a ver la cesta (Ex 2,5-6), cuyo rol puede considerarse secundario.

10) Llegados a este punto, observamos que el río, nunca mencionado por su nombre propio, puede ser considerado un personaje no solo por la importancia geográfica y económica que tuvo y tiene en Egipto, sino también por su variado rol actancial en la narración.

En este sentido, el río es un personaje individual y protagonista del relato. En Ex 1,22 aparece como el lugar donde deben morir los recién nacidos israelitas. Pero allí es donde es dejado Moisés por su madre en un cesto ${ }^{39}$ para huir de la muerte. El río, fuente de vida para los egipcios, pero que el faraón enrola como verdugo de los niños hebreos, no puede con el futuro libertador (cf. Ex 2,3-5), sino que incluso será la vía por la cual el niño llegará sano y salvo hasta la mismísima corte del rey ${ }^{40}$.

Finalmente, el nombre del héroe hace referencia, de modo indirecto, al río. Así, el pequeño "protagonista", ya desde sus comienzos, si bien de forma indirecta, aparece ganando la primera prueba: sobrevive a las aguas asesinas.

11) El resto de los personajes femeninos son muchos en el macrotexto. En Ex 1,2-4 encontramos una breve genealogía, que divide a los hijos de Jacob en cuatro grupos (esto se aprecia mejor en la construcción hebrea), que coinciden con sus dos esposas y las dos esclavas: Raquel, Lea, Bilá y Silpá ${ }^{41}$. A diferencia de las genea-

39 Nos parece importante mencionar que la palabra utiliza para referirse al cesto (o, valga la redundancia, el "moisés") es la misma que se utiliza para referirse al arca de Noé $(G n 6,14 ; 9,18)$. Un término que sin duda el lector del Pentateuco conoce y que actúa como analepsis: Moisés rememora a Noé y el diluvio.

40 Como vemos, la ironía sigue recorriendo todo el macrotexto: el todopoderoso Nilo, a pesar del faraón, no pierde en la mano del narrador su esencia, que es ser fuente de vida.

${ }^{41}$ Cf. Gn 35,23-26. 
logías, esta no está armada cronológicamente, sino por sus madres, lo cual es un modo de nombrar indirectamente a las mujeres. Acerca de las mujeres que aparecen en Ex 1,15-22, ya hemos hablado más arriba.

En Ex 2,1-10 encontramos un grupo de mujeres que salvan la vida de Moisés desobedeciendo al faraón. Por tanto, en el macrotexto queda más en evidencia que las mujeres están emparentadas con la astucia, la vida y su protección ${ }^{42}$, y contrastan tanto con el maléfico actuar del faraón como con la pasividad del padre de Moisés y su obvia inactividad.

Vuelve a sorprender en este punto la poca relevancia actoral de los personajes masculinos del macrotexto, a excepción del faraón y, por supuesto, Elohim.

Finalmente, después de este recorrido por el universo de los actores del macrotexto, observamos que el faraón, de modo directo o indirecto, es el único personaje que abarca casi toda la narración. Pese a que su figura es poderosa y opresora, es burlado por el pueblo, que crece; por las comadronas, que no siguen sus órdenes; por Dios, que da vida; por la madre y la hermana de Moisés, que también desobedecen. Y, por último, por su hija, que adopta un niño hebreo.

En el macrotexto, el deseo del faraón es destruir la descendencia del pueblo hebreo, la cual es defendida por las mujeres y por Dios. Incluso cuando parecería que el faraón está venciendo, un niño hebreo nace y es adoptado por su hija; un niño que luego liberará a su pueblo y será el gran profeta de Israel.

\section{Conclusión}

El análisis narrativo nos pone en contacto con una cantidad de elementos y detalles que podrían ser pasados por alto en una lectura rápida o por un análisis de otro tipo.

Pese a su brevedad -solo ocho versículos-, el texto muestra un abanico de significados. Juzgamos que el autor eligió con gran cuidado cada término. Ensambló las oraciones con maestría, sabiendo hacer del texto una

42 “Las comadronas de Ex 1 y la nodriza o ama de cría [mêneqet] de Ex 2 aparecen como resistentes a la opresión y al genocidio decretados por el faraón. Su astucia salva al pueblo de Israel y permite continuar los planes de Yahvé", DE LEóN AzCÁRATE, “Enfermedad”, 73. 
obra que conecta el pasado, el presente y el futuro del pueblo, ofreciendo además al lector una historia llena de intriga, coraje, ironía, sabiduría y fe.

La perícopa nos hace vibrar, sufrir con el pueblo hebreo e incluso sentir ira ante un rey/faraón que decreta la muerte de los varones recién nacidos. Como también nos hace ponernos de parte de las parteras y apoyar sus acciones, que no se ajustan a las órdenes asesinas del monarca.

El texto nos hace sentir antipatía y rechazo nuevamente, pues, pese al actuar de las parteras y la bendición de Dios, el monarca recrudece sus órdenes.

El método narrativo nos ha permitido ahondar en la comprensión de la perícopa estudiada, no solo por ofrecer otro punto de vista a la hora de analizar el texto, sino también por poner de manifiesto elementos que el método histórico-crítico podría pasar por alto.

Este método nos permite privilegiar el texto como un todo (sincronía) donde, si bien las partes pueden diferenciarse, prima la visión de conjunto y la unidad del relato. Su aplicación nos ayuda a apreciar mejor el flujo del relato, el desarrollo de las secuencias; conocer a los personajes, sus características, sus relaciones entre sí y sus transformaciones a lo largo del relato; ponernos en el lugar del lector: conocer algo de los sentimientos que experimenta ante la historia, su posición; la temporalidad del relato, etc. Si el método histórico-crítico nos permite conocer la figura del faraón en Egipto y su imagen en la Escritura, el método narrativo nos ha permitido ver su maldad, el rechazo que despierta, su relación con otros personajes, etc.

Con nuestra afirmación no queremos decir que el método narrativo sea mejor o peor que el histórico-crítico. Ambos, pensamos, se complementan, iluminan y completan mutuamente. Un análisis diacrónico se complementa con uno sincrónico. Permitiendo un juego entre el todo y las partes. Como quien mira un tapiz. De lejos vemos un dibujo con formas y colores en armonía y equilibrio; de cerca vemos cómo se entretejen los hilos, su textura, el material con que están hechos y sus colores individuales y característicos.

Ex 1,15-22 nos pone de frente ante la lucha entre el poder de la vida y el poder de la muerte. Lucha llevada a cabo, en este caso, por dos simples pero valientes y sagaces comadronas. Ellas no titubean ni flaquean ante el poder del faraón. Por el contrario, por su temor de Dios ellas defienden la vida, transformándose en un canto de esperanza ante situaciones donde la muerte pareciera tener la última palabra.

No podemos soslayar que este texto se emparenta con un tema de gran actualidad: la despenalización del aborto, la objeción de conciencia 
ante leyes y prácticas médicas abortistas, la eutanasia, etc. No es nuestra intención adentrarnos aquí en cuestiones que atañen a la moral, solo ponemos de relieve que existen profesionales de la salud que defienden el don de la vida, al igual que las parteras, con valentía e ingenio, persuadiendo y aconsejando sabiamente, incluso a costa de poner en juego sus profesiones ${ }^{43}$.

El relato es una gran lección de humanidad, de lucha contra la opresión, de defensa de la vida, de cuidado del débil. Pero también es texto religioso que enseña acerca del valor del temor de Dios, la fe puesta en acción, la divina Providencia y la fidelidad de Dios a su promesa.

\section{Bibliografía}

An Asian Group Work, "An Asian Feminist Perspective, the Exodus Story (Exodus 1:8-22; 2:1-10)", en R. S. SugirtharajaH (ed.), Voices from the Margin: Interpreting the Bible in the World, New York 2006, 255-266.

Alonso Schökel, L., Biblia del peregrino. Antiguo Testamento. Prosa. Edición de estudio. I, Estella 1996.

ANDiñaCH, P., El libro del Éxodo, Salamanca 2006.

Auzou, G., De la servidumbre al servicio. Estudio del libro del Éxodo, Madrid 1974.

Barnawi, N. - Richter, S. - Habib, F., "Midwifery and Midwives: A Historical Analysis", Journal of Research in Nursing and Midwifery 8 (2013) 114-121.

Cassuto, U., A Commentary on the book of Exodus, Jerusalem 1967.

Childs, B. S., El libro del Éxodo, Estella 2000.

Exum, J. C., "'You Shall Let Every Daughter Live': A Study of Exodus 1:8-2:10", Semeia 28 (1983) 63-82.

Flavio Josefo, Obras completas. I: Vida. Antigüedades judías, Libros I-VI, Buenos Aires 1961.

García BaChManN, M., “¿Qué hacían mientras tanto las mujeres hebreas (Éxodo 1-2)?”, Cuadernos de Teología 18 (1999) 7-20.

43 “Para 'Luteranos por la vida de Australia', las parteras contemporáneas son los doctores, enfermeras, docentes de enfermería y otro personal médico que se encuentran ante el dilema moral de apoyar o participar en abortos o no. De modo similar, en su encíclica, Evangelium vitae, el papa Juan Pablo II cita a las parteras como ejemplo autorizado de resistencia ante las leyes humanas injustas tratándose del aborto y la eutanasia", LANGSTON, Exodus, 19. 
GinzBerg, L., The Legends of the Jews, Philadelphia 1980.

Giron Blanc, L. F., Midrás Éxodo Rabbah I (Biblioteca Midrásica 8), Valencia 1989.

Hasan, I. - Zulkifle, M. - Ansari, A. H. - Sherwani, A. M. K. - ShaKIR, M., "History of Ancient Egyptian Obstetrics \& Gynecology: A Review", Journal of Microbiology and Biotechnology Research 1 (2011) 35-39.

Langston, S. M., Exodus through the Centuries, Oxford 2006.

Lattus, J. -CARreÑo, E., "El asiento del nacimiento", Revista de Obstetricia y Ginecología Hospital Santiago Oriente Dr. Luis Tisné Brousse 5 (2010) 41-50.

León AzCÁrate, J. L. DE, “'Yo soy Yahvé, el que te sana' (Ex 15,26). Enfermedad y salud en la Torá", Theologica Xaveriana 171 (2011) 65-96.

LeÓn-Dufour, X., Vocabulario de teología bíblica. Ed. rev. y ampl., Barcelona 1990.

Marguerat, D. - Bourquin, Y., Cómo leer los relatos bíblicos. Iniciación al análisis narrativo, Santander 2000.

Martínez Saiz, T. - Pérez Fernández, M., Traducciones arameas de la Biblia. Los targumim del Pentateuco. II. Éxodo, Estella 2011.

McGeough, K., "Birth Bricks, Potter's Wheels, and Exodus 1,16", Biblica 87 (2006) 305-318.

Morschauser, S., "Potter's Wheel and Pregnancies: a note on Ex 1,16", Journal of Biblical Literature 122 (2003) 731-733.

Pontificia Comisión Bíblica, La interpretación de la Biblia en la Iglesia, Madrid ${ }^{5} 1998$.

Porcile Santiso, M. T., Con ojos de mujer. Lo femenino en la teología y en la espiritualidad contemporáneas, Buenos Aires 2008.

Römer, Th., "Moses and the Women in Exodus 1-4", Indian Theological Studies 52 (2015) 237-250.

Roth, A. M. - Roehrig, C. H., "Magical Bricks and the Bricks of Birth", The Journal of Egyptian Archaeology 88 (2002) 121-139.

Sicre, J. L., El Pentateuco: introducción y textos, Buenos Aires 2004.

SKA, J.-L., "Il diritto e la legge: una distinzione fondamentale nella Bibbia", La Civiltà Cattolica 3737 (2006) 468-479.

-, Introducción a la lectura del Pentateuco, estella 2001.

Sheriffs, D., "Moving on with God: Key motifs in Exodus 13-20," Themelios 15 (1990) 49-60.

El Talmud de Babilonia. Tratados Nazir-Sota, Buenos Aires 2004.

TÖPfER, S., "The Physical Activity of Parturition in Ancient Egypt: Textual and Epigraphical Sources”, Dynamis 34 (2014) 317-335. 
VAux, R. DE, Historia antigua de Israel. Desde los orígenes a la entrada en Canaán I, Madrid 1974.

WeEms, R., "The Hebrew women are not like the Egyptian women: the ideology of race, gender and sexual reproduction in Exodus 1", Semeia 59 (1992) 25-34.

Wicke, D. W., "The Literary Structure of Exodus 1:2-2:10”, Journal for the Study of the Old Testament 24 (1982) 99-107.

[recibido: 04/06/18 - aceptado: 30/09/18] 